J. Lake Sci. (湖泊科学), 2010, 22(1): 63-69

http://www. jlakes.org. E-mail: jlakes@niglas.ac.cn

(c) 2010 by Journal of Lake Sciences

\title{
“引江济太”水系有色溶解有机质的特征与来源”
}

\author{
陈锡超, 纪颖琳,胡 青, 黄清辉 ${ }^{* *}$ \\ ( 同济大学环境科学与工程学院长江水环境教育部重点实验室,上海 200092)
}

\begin{abstract}
摘 要: 在 “引江济太”水系的调查基础上, 分析了有色溶解有机质 (CDOM) 的吸收光谱、苂光特性及其主要来源, 探讨了 $\mathrm{CDOM}$ 与 $\mathrm{pH} 、 \mathrm{DO}$ 、叶绿素 $\mathrm{a}$ 等水质指标的关系. 结果表明: 水体吸收系数 $a(355)$ 与 CDOM 浓度呈显著正相关,均具有明显 的空间差异, 它们在河道出人湖口及开阔湖区较低, 而在望虞河和太浦河中游较高, 这显然与中游河道受纳了两岸污水 有关, $S$ 值也表明望虞河受外源输人影响最大. 通过三维荧光激发一发射矩阵 (EEM) 分析, 发现了 5 种苂光团, 包括 2 种类 蛋白苂光团和 3 种类腐殖质荧光团, 其中类蛋白苂光 (特别是 $\mathrm{T}$ 峰) 明显强于类腐殖质苂光. 研究发现, 水体 DO 浓度、pH 值均随 CDOM 浓度呈指数函数递减. 苂光指数 $(F I)$ 明显偏向生物来源 (约 1.9), 因此, “引江济太”水系 CDOM 以生物的 本地生产为主, 河道局部污染水体中的类腐殖质苂光可能来源于污水微生物对藻类产生的溶解有机质的转化, 在局部河 道中也有一定的外源输人.
\end{abstract}

关键词: 引江济太;有色溶解有机质;吸收系数;三维苂光;苂光指数

\section{Characteristics and sources of CDOM in the drainage system of Water Diversion from Yangtze River to Lake Taihu}

CHEN Xichao, JI Yinglin, HU Qing \& HUANG Qinghui

( Key Laboratory of Yangtze River Water Environment of Ministry of Education, College of Environmental Science and Engineering, Tongji University, Shanghai 200092, P. R. China)

Abstract: Based on the investigation of the water body of the drainage system of Water Diversion from Yangtze River to Lake Taihu, the absorbance spectrum and fluorescent characteristics of chromophoric dissolved organic matter (CDOM) and its source were analyzed. The correlation between CDOM and some water quality indexes including $\mathrm{pH}$, DO and chlorophyll-a concentrations was discussed. The results showed that CDOM concentrations were positively correlated with their absorption coefficients at $355 \mathrm{~nm}$ with significantly spatial differences. $S$ values also indicated that Wangyu River was affected by terrestrial input much more than other areas. Five fluorophores were observed by three dimensional excitation emission matrix (3DEEM) fluorescence spectroscopy including UVC protein-like, UVB protein-like, UVA humic-like, UVB humic-like, and UVC humic-like fluorescent signals. The fluorescence intensities of protein-like fractions (especially peak $\mathrm{T}$ ) were much stronger than those of humic-like fractions. Both $\mathrm{pH}$ and DO concentrations exponentially decreased with CDOM concentrations. According to the correlation between chlorophyll-a concentrations and CDOM concentrations, humic-like fluorescent signal might transformed by microorganisms. Fluorescence index had a value of about 1.9, therefore, CDOM could be dominated mainly by local microbial sources, and terrestrial input could be also a source of CDOM for part of the rivers.

Keywords: Water Diversion from Yangtze River to Lake Taihu; CDOM; absorption coefficient; 3DEEM; fluorescence index

溶解有机质 (DOM) 广泛存在于各类水体, 含有丰富的碳、氮、磷等营养元素, 在湖泊各种物理、化学和生 物及水华暴发过程中都扮演着非常重要的角色 ${ }^{[1-3]}$. 有色溶解有机质 (CDOM) 又称黄色物质, 是可以用吸收 光谱或苂光光谱技术进行检测的 DOM 组分 ${ }^{[4]}$. 如今, 三维苂光光谱 (3DEEMs) 作为一种非常灵敏的 CDOM

* 国家自然科学基金项目 (40601095,20777021) 和中俄国际科技合作项目 (2007DFR90050) 联合资助. 2009-04-16 收稿;2009-09-08 收修改稿. 陈锡超,男,1987 年生,学士;E-mail: 061443@ tongji. edu. cn.

** 通讯作者;E-mail: qhhuang@ tongji. edu.cn. 
分析技术越来越受到青睐, CDOM 激发出的不同类型 (类腐殖酸、类蛋白质等) 的菼光信号可用于解析其来

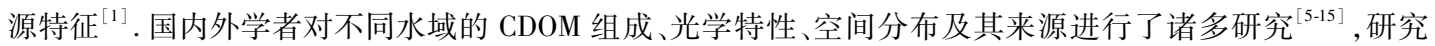
对象从海洋向内陆水域拓展, 近年来高原地区和相对贫营养的湖泊也开始受到关注 ${ }^{[13-14]}$.

目前太湖面临着严重的富营养化问题, 其环境和生态问题引起越来越多的关注, 特别是 2007 年 5 月至 6 月的 “太湖蓝藻水华事件” 对无锡人民饮用水源带来了严重影响, 引起了全球的关注 ${ }^{[16-17]}$. 蓝藻水华死亡 腐烂降解会释放大量 DOM, 从而消耗水中的溶解氧, 使得厌氧条件下藻类代谢产生二甲基三硫化合物等恶 臭物质 ${ }^{[18]}$. 从 2000 年开始, 太湖流域管理局实施了“引江济太”调水方案, 以实现“以动治静, 以清释污, 以 丰补枯, 改善水质”. 本文对 “引江济太”工程主要河湖水系进行了调查, 讨论营养盐等水质指标和 CDOM 分 布特征与来源, 以期为太湖富营养化的治理和“引江济太”工程的进一步实施提供参考.

\section{1 材料与方法}

2008 年 9 月 5-7 日对“引江济太” 河湖水系共 22 个点位的表层水进行了采集, 其中 $1^{\#}$ 位于长江, $2^{\#}-$ $10^{\#}$ 位于望虞河, $11^{\#}-16^{\#}$ 位于太湖东区, $17^{\#}-21^{\#}$ 位于太浦河, $22^{\#}$ 位于淀山湖, 具体位置见图 1 , 采样点经纬度 由麦哲伦 GPS 确定.

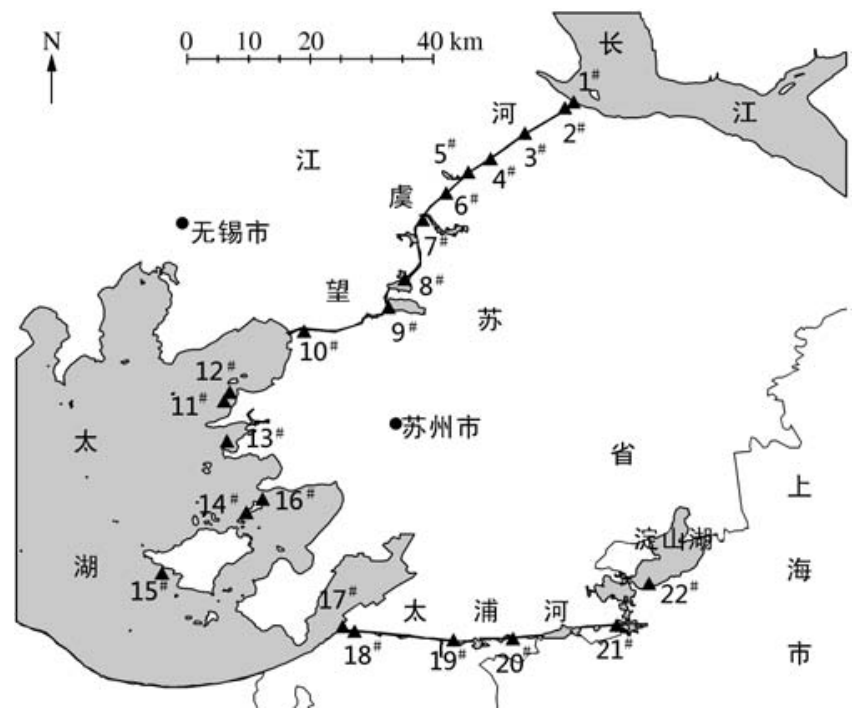

图 1 “引江济太”水系采样点分布

Fig. 1 Location of sampling sites of the drainage system from Yangtze River to Lake Taihu

$\mathrm{pH} 、 \mathrm{DO}$ 和电导率现场使用便携式多参数水质测定仪 (HQ40D, 美国 HACH) 测定. CDOM 浓度用有色溶解 有机质苂光分析仪 (MicroFlu-CDOM, 德国 TRIOS 公司) 测定, 使用国际上通用的硫酸奎宁作为 CDOM 的标准 进行标定, CDOM 浓度用硫酸奎宁当量浓度计量, 单位 $\mu \mathrm{g} / \mathrm{L}$. 利用浮游植物荧光仪 (Phyto-PAM, 德国 WALZ 公 司) 现场测定浮游植物活体叶绿素 a 浓度. 该仪器利用 4 种不同颜色的光源 $(470 \mathrm{~nm} 、 520 \mathrm{~nm} 、 645 \mathrm{~nm} 、 665 \mathrm{~nm}$ ) 激 发出的半同步荧光信号可以测量蓝藻、绿藻和硅/甲藻的叶绿素 a 浓度, 检出限为 $0.1 \mu \mathrm{g} / \mathrm{L}$.

在每个观测点采集约 $500 \mathrm{ml}$ 的水样,一部分加硫酸酸化至 $\mathrm{pH}<2$ 后装人聚乙烯瓶内, 用于总磷、总氮测 定; 另一部分现场微孔滤膜 ( 混合纤维素酯, 孔径 $0.45 \mu \mathrm{m}$ ) 过滤后装人 $40 \mathrm{ml}$ 高温预灼过的棕色玻璃瓶内, 并 置于冷藏箱内. Milli-Q 超纯水作空白对照, 与过滤后的水样分别利用苂光光谱分析仪 (F-4500, 日本 Hitachi 公司) 进行三维苂光光谱扫描, 扫描范围为: $E x=225-400 \mathrm{~nm}, E m=250-550 \mathrm{~nm}$, 扫描间隔均为 $3 \mathrm{~nm}^{[15]}$; 样 品光谱数据均作扣除空白处理, 苂光强度进行 Raman 归一化处理 ${ }^{[19]}$, 单位统一为R. U. $\left(\mathrm{nm}^{-1}\right)$, 所得激发发射矩阵 EEM 数据用 MATLAB R2007b 软件 (The MathWorks Inc.) 绘制成等值线图,这些图中已消除Raman 散射和大部分 Rayleigh 散射 ${ }^{[19]}$.

用紫外-可见分光光度计 (TU-1901, 北京普析通用有限公司) 进行全波长扫描, 测定吸光度, 波长范围为 
$200-700 \mathrm{~nm}$. 将吸光度换算为各波长处的吸收系数 ${ }^{[20]}$ :

$$
a(\lambda)=2.303 A(\lambda) / 0.01
$$

式中, $a(\lambda)$ 为波长 $\lambda$ 处的吸收系数 $\left(\mathrm{m}^{-1}\right) ; A(\lambda)$ 为波长 $\lambda$ 处的吸光度; 0.01 为光程路径 $(\mathrm{m})$. 通常可采用 $355 \mathrm{~nm}$ 处的吸收系数 $a(355)$ 来表征 CDOM 浓度. CDOM 在紫外-可见光波段的吸收基本上呈指数衰减规律, 并遵循如下方程 ${ }^{[20-21]}$ :

$$
a(\lambda)=a\left(\lambda_{0}\right) \mathrm{e}^{S\left(\lambda_{0}-\lambda\right)}+K
$$

式中, $\lambda$ 为波长 $(\mathrm{nm}) ; \lambda_{0}$ 为参照波长 $(\mathrm{nm}) ; S$ 为指数函数曲线斜率参数, 与 $\mathrm{CDOM}$ 组成结构有关 $\left(\mathrm{nm}^{-1}\right) ; K$ 是残余散射或残留噪声偏移量 $\left(\mathrm{m}^{-1}\right)$. 在 $300-650 \mathrm{~nm}$ 波段处使用 Origin 7.5 软件 (OriginLab Co., 美国) 进 行指数函数拟合.

\section{2 结果与讨论}

\section{1 “引江济太”水系水质特征及其紫外吸收特性}

“引江济太”工程从长江引水到太浦河出水, 水系的水质特征差异显著. 溶解氧浓度范围为 $2.00-$ $8.08 \mathrm{mg} / \mathrm{L}$, 电导率范围为 $340-1029 \mu \mathrm{S} / \mathrm{cm}$, 总氮浓度范围为 $0.36-1.64 \mathrm{mg} / \mathrm{L}$, 总磷浓度范围为 $0.03-$ $0.21 \mathrm{mg} / \mathrm{L}$ (表 1 ). CDOM 浓度也在各水域之间具有明显的差异 (表 1 ), 河水尤其是望虞河 $4^{\#}-8^{\#}$ 明显偏高, 这些点水样同时具有较高的电导率和较低的溶解氧浓度 (图 2), 表明该处河水可能受两岸城镇生活污水、工 业废水和农业面源污染影响 ${ }^{[26]}$, 而开阔湖区及河道出/入湖口水体的 CDOM 浓度相对来说要低一些.

表 1 引江济太水系水体的基本理化特征

\begin{tabular}{|c|c|c|c|c|c|c|c|c|}
\hline $\begin{array}{l}\text { 采样位置 } \\
\text { (样品数) }\end{array}$ & $\mathrm{pH}$ & $\begin{array}{l}\text { 溶解氧 } \\
(\mathrm{mg} / \mathrm{L})\end{array}$ & $\begin{array}{l}\text { 电导率 } \\
(\mu \mathrm{S} / \mathrm{cm})\end{array}$ & $\begin{array}{c}\text { 叶绿素 a } \\
(\mu \mathrm{g} / \mathrm{L})\end{array}$ & $\begin{array}{c}\text { 总氮 } \\
(\mathrm{mg} / \mathrm{L})\end{array}$ & $\begin{array}{c}\text { 总磷 } \\
(\mathrm{mg} / \mathrm{L})\end{array}$ & $\begin{array}{l}a(355) \\
\left(\mathrm{m}^{-1}\right)\end{array}$ & $\begin{array}{c}\text { CDOM } \\
(\mu \mathrm{g} / \mathrm{L})\end{array}$ \\
\hline $\begin{array}{c}\text { 长江 } \\
(n=1)\end{array}$ & 7.61 & 5.91 & 346 & 25.5 & 0.73 & 0.14 & 1.20 & 5.33 \\
\hline $\begin{array}{l}\text { 望虞河 } \\
(n=9)\end{array}$ & $\begin{array}{c}7.40 \\
(7.14-7.76)\end{array}$ & $\begin{array}{c}4.20 \\
(2.00-6.03)\end{array}$ & $\begin{array}{c}743 \\
(348-1029)\end{array}$ & $\begin{array}{c}101 \\
(17.9-190)\end{array}$ & $\begin{array}{c}1.14 \\
(0.85-1.64)\end{array}$ & $\begin{array}{c}0.17 \\
(0.14-0.21)\end{array}$ & $\begin{array}{c}5.86 \\
(1.5-10.2)\end{array}$ & $\begin{array}{c}16.72 \\
(4.88-26.4)\end{array}$ \\
\hline $\begin{array}{c}\text { 太湖东区 } \\
(n=6)\end{array}$ & $\begin{array}{c}7.90 \\
(7.43-8.20)\end{array}$ & $\begin{array}{c}7.20 \\
(6.18-8.08)\end{array}$ & $\begin{array}{c}473 \\
(437-496)\end{array}$ & $\begin{array}{c}25.9 \\
(15.5-35.4)\end{array}$ & $\begin{array}{c}0.40 \\
(0.36-0.45)\end{array}$ & $\begin{array}{c}0.06 \\
(0.031-0.090)\end{array}$ & $\begin{array}{c}3.14 \\
(1.13-8.64)\end{array}$ & $\begin{array}{c}6.14 \\
(4.04-8.36)\end{array}$ \\
\hline $\begin{array}{l}\text { 太浦河 } \\
(n=5)\end{array}$ & $\begin{array}{c}7.30 \\
(7.08-7.49)\end{array}$ & $\begin{array}{c}5.20 \\
(3.38-7.57)\end{array}$ & $\begin{array}{c}372 \\
(340-412)\end{array}$ & $\begin{array}{c}25.6 \\
(19.8-33.7)\end{array}$ & $\begin{array}{c}0.62 \\
(0.38-0.88)\end{array}$ & $\begin{array}{c}0.08 \\
(0.037-0.12)\end{array}$ & $\begin{array}{c}3.46 \\
(0.67-5.23)\end{array}$ & $\begin{array}{c}9.30 \\
(5.63-12.6)\end{array}$ \\
\hline $\begin{array}{l}\text { 淀山湖 } \\
(n=1)\end{array}$ & 7.46 & 6.03 & 624 & 21.0 & 1.02 & 0.18 & 3.59 & 10.58 \\
\hline
\end{tabular}

Tab. 1 Basic features of the drainage system of Water Diversion from Yangtze River to Lake Taihu

CDOM 吸收系数 $a(355)$ 与其浓度呈显著线性相关 性 $\left(r=0.77, P<0.0001, n=22\right.$ ) ( 图 3), 其中 $11^{\#}$ 样品的 $a(355)$ 出现极高值 $(8.64)$, 根据现场记录, 该点在贡湖 湾东渚岸边有水草和浮叶植物生长. 长江河水比较干净, 其中 CDOM 浓度及其吸收系数均较低. 而望虞河和太浦 河的吸收系数普遍高于长江水体和太湖东区水体, 当然, 与人湖的望虞河相比, 出湖的太浦河 CDOM 浓度及其吸 收系数明显降低. 望虞河电导率、叶绿素 a、总氮、总磷等 指标也均高于太湖东区, 主要是因为采样期间, 望虞河没 有从长江引水, 水位较低, 两岸尤其是西岸受污染河网汇 人望虞河 ${ }^{[22-23]}$. 因此, “引江济太” 工程可引入较优质的 长江水进人太湖, 但关键需要解决好望虞河两岸的污水 出路及其内源污染负荷问题.

“引江济太”水系的 $S$ 值变化较大, 在 $14.95-$

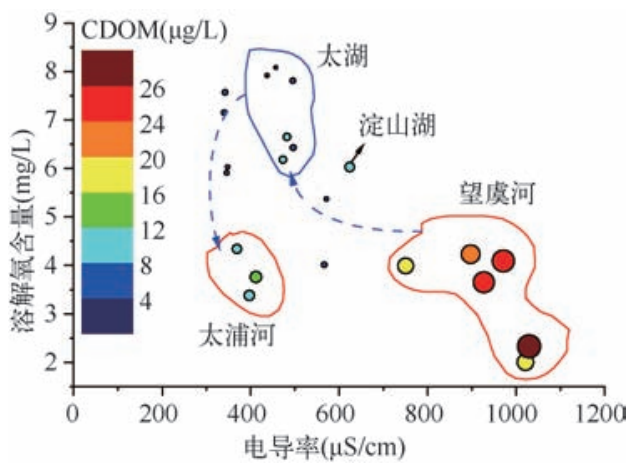

图 $2 \mathrm{CDOM}$ 浓度与溶解氧浓度和 电导率之间的关系

Fig. 2 CDOM concentrations versus DO concentrations and conductivities 
$32.09 \mu \mathrm{m}^{-1}$ 之间, 平均为 $20.92 \mu \mathrm{m}^{-1}$ (图 3). 有研究指出 $S$ 值的差异是由于 $C D O M$ 来源不同造成的, 若胡敏 酸 ( humic acid) 比例越高、富里酸 (fulvic acid) 比例越低,则 $C D O M$ 分子量越大、 $S$ 值越小 ${ }^{[24,25]}$. 来自于人为排 放和河流携带有机成分输人的 CDOM, 含有胡敏酸的比例较大, 会导致 $S$ 值偏低 ${ }^{[24-25]}$. 本研究发现, 望虞河、 太湖东区、淀山湖、太浦河、长江的 $S$ 值依次增加, 说明望虞河 CDOM 中含大分子量的胡敏酸比例较高, 受外 源输人的影响最大. 处于太浦河上游 $18^{\#}$, 受外源影响较小, $S$ 值最大, 其 CDOM 以生物自身降解的富里酸为 主, 而富里酸的吸收系数较小, CDOM 浓度较低, 使得 $a(355)$ 反而最小. 还有研究发现, CDOM 的吸收系数与 $S$ 值存在一定的负相关关系, 而这种负相关并不是绝对的, 因胡敏酸与富里酸的比例变化存在一定的不规则 性 ${ }^{[25]}$. “引江济太” 水系水体 CDOM 特征参数 $a(355)$ 与 $S$ 值的关系 (图 4) 表明, 二者呈现负相关关系, 使用 线性和指数拟合发现, 指数函数拟合 $(r=0.82)$ 的相关性比线性拟合 $(r=0.70)$ 更好.

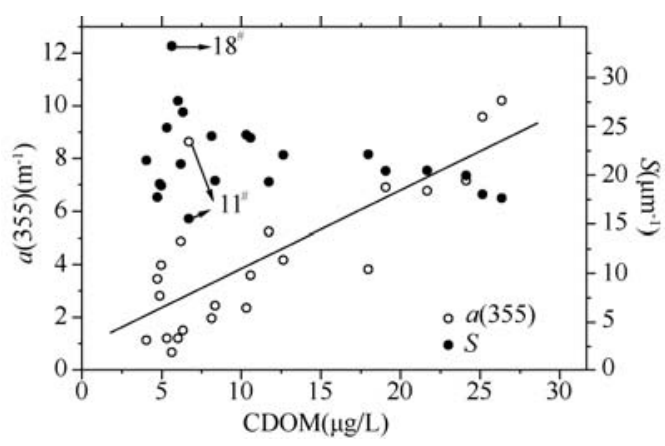

图 3 吸收系数和光谱斜率与 CDOM 含量之间的关系

Fig. 3 CDOM content versus absorption coefficients and spectra slope

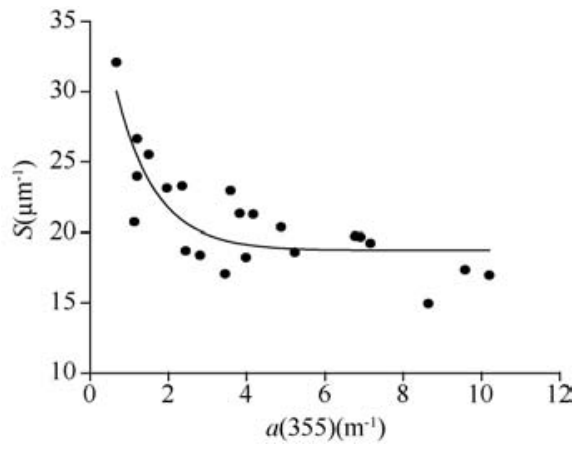

图 $4 \mathrm{CDOM}$ 特征参数 $a(355)$ 与 $S$ 值的关系

Fig. 4 Correlation between $a(355)$ and spectra slope

\section{$2.2 \mathrm{CDOM}$ 的荧光特性}

从“引江济太”水系不同水域典型水样的三维荧光光谱图 (图 5) 检出了 5 种苂光团 ${ }^{[1,15,19]}$, 包括紫外光 $C$ 区类蛋白菼光团 (峰 $S, T$ ) 、紫外光 B 区类蛋白苂光团 (峰 T)、紫外光 A 区类腐殖质苂光团 ( 峰 $C$ )、、紫外光 B 区类腐殖质苂光团、紫外光 C 区类腐殖质苂光团 (峰 A), 不同水域苂光峰值出现的位置和强度的不一样 暗示了不同水域 $\mathrm{CDOM}$ 的来源和组成不一样 ${ }^{[1,26]}$. 从苂光强度来看, 以 UVC 类蛋白苂光峰 $\mathrm{T}$ 最强、 UVB 类 蛋白苂光峰 $\mathrm{S}$ 次之; 相对来说, 类腐殖质苂光峰 $\mathrm{A}$ 和 $\mathrm{C}$ 的强度要弱很多, 主要出现在两条引排水河道中部的 一些采样点, 特别是在 $4^{\#} 、 7^{\#} 、 8^{\#}$ 水样中类腐殖质苂光峰较明显, $7^{\#} 、 8^{\#}$ 的光谱斜率 $S$ 值偏低, 这些类腐殖质苂 光受外源影响较大. 不过, 河水样品的类蛋白苂光明显强于类腐殖质苂光, 不少研究表明污水的输人也能够 引起水体 UVB 类蛋白组分的 S 峰、T 峰等苂光信号增强 ${ }^{[19,27-28]}$, 最近在长江口、黄浦江等水体的研究中也发 现类似的规律 ${ }^{[15]}$.

\subsection{CDOM 的来源分析}

对“引江济太” 水系水体中的浮游植物进行活体叶绿素苂光测定, 结果表明硅藻 + 甲藻的比例最高, 绿 藻次之, 蓝藻的比例很低 (图 6). 众多研究表明, 浮游植物产生的 DOM 多数不具有苂光特性, 但是在水体微 生物作用下可转化为具有苂光特性的 $\mathrm{CDOM}^{[3,29]}$, 而且会产生类腐殖质苂光信号 ${ }^{[3]}$. 各点浮游植物的叶绿素 $\mathrm{a}$ 浓度与 CDOM 浓度呈显著线性相关性 $(r=0.74, P<0.0001, n=22)$ (图 7), 这在夏季水华暴发时经常观测 到 ${ }^{[4-5,30]}$, 虽然这次采样时没有水华暴发, 但夏末 CDOM 的浓度还是会受浮游植物变化的影响, $5^{\#} 、 10^{\#}$ 的数据 比较离散, 尤其是 $10^{\#}$ 硅藻 + 甲藻含量为零, 而是绿藻占据了主要地位, 这与现场水体发绿, 漂有大量藻类吻 合. 因此, 本研究在河道局部污染水体观测到的一定强度的类腐殖质荧光, 还可能来源于藻类 DOM 在污水 微生物作用下转化的 CDOM. 

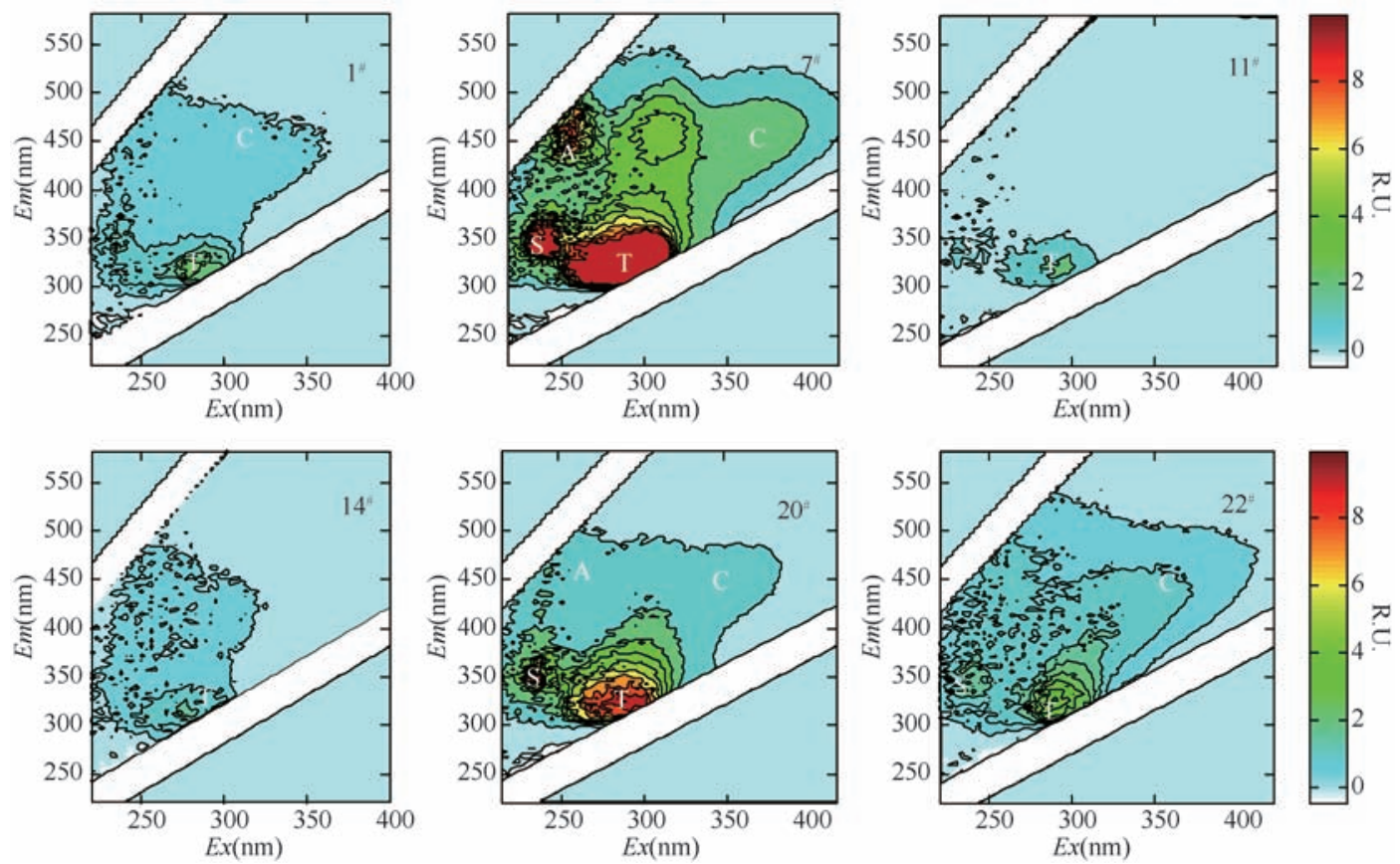

图 5 典型水样 $\mathrm{CDOM}$ 的三维荧光光谱

Fig. 5 EEMs spectra of CDOM from typical sampling sites

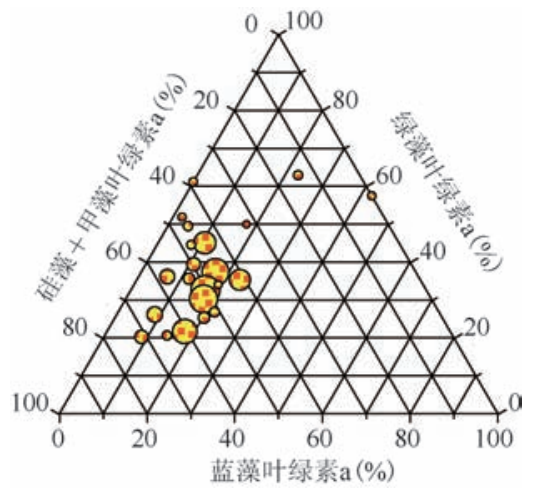

图 6 藻类结构组成及其与 CDOM 含量的关系

Fig. 6 Algae composition and its relationship with CDOM concentrations

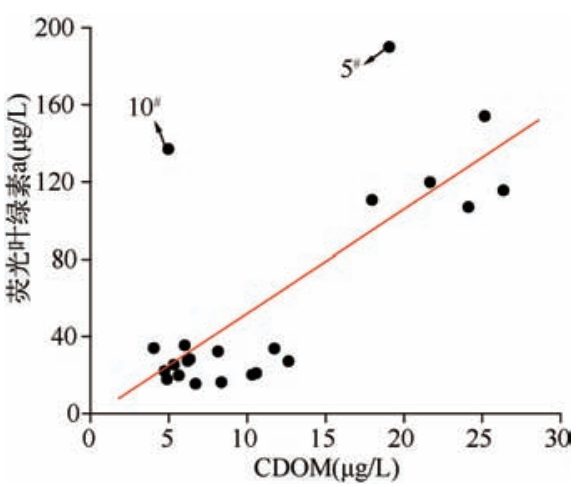

图 7 叶绿素 a 与 CDOM 的相关性

Fig. 7 Correlation between chlorophyll-a and CDOM

苂光指数 $(F I)$ 可用于表征 DOM 中的腐殖质的来源 ${ }^{[10,31]}$, 新改进的 $F I$ 定义为 $E x=370 \mathrm{~nm}$ 时, 苂光发射 光谱强度在 $470 \mathrm{~nm}$ 和 $520 \mathrm{~nm}$ 处的比值 ${ }^{[10]}$, 经验上它有两个端值, 靠近 1.4 为陆源输人的腐殖质类物质, 靠 近 1.9 为生物来源的类蛋白物质 ${ }^{[10,15,31]}$, 也有污水输人的大量类蛋白组分 ${ }^{[15]}$. 大部分样品的苂光指数处于 1.9 一端, 说明本研究水系 CDOM 以本地的生物降解类蛋白物质来源为主, 这与三维荧光分析中类蛋白苂光 强于类腐殖质荧光一致, 在局部河道也有一定的外源输人, 导致类蛋白苂光峰进一步增强, 这与望虞河流经 城镇的生活污水和工业废水排放有关; DO 浓度、 $\mathrm{pH}$ 值均随 CDOM 浓度呈指数函数递减的关系 $(r$ 分别为 $0.81 、 0.75, n=22$ ), 而且大致可分成两个区域 $\mathrm{A}$ 和 $\mathrm{B}$ (图 8, 图 9): 在 CDOM 浓度较低、 $\mathrm{pH}$ 和 DO 值较高时, $\mathrm{CDOM}$ 的 $F I$ 指数较小, 分子芳香性较强; 反之, 在 $\mathrm{CDOM}$ 浓度较高、 $\mathrm{pH}$ 和 $\mathrm{DO}$ 值较低时, 受污水输人影响, $\mathrm{CDOM}$ 的 $F I$ 指数偏大, 分子芳香性较小 ${ }^{[15,27]}$. 


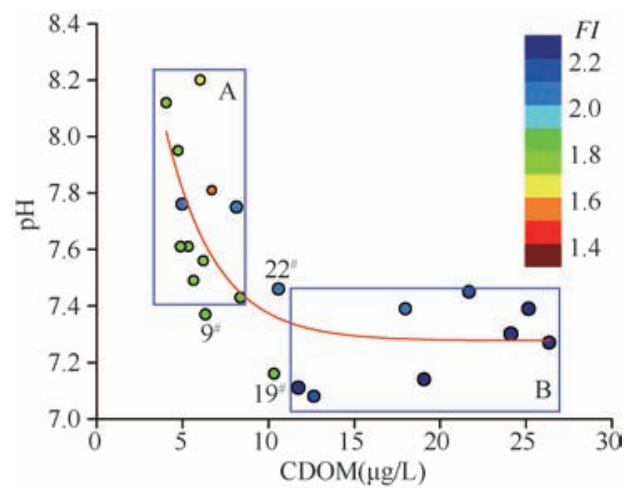

图 8 菼光指数与 $\mathrm{pH} 、 \mathrm{CDOM}$ 浓度的关系

Fig. 8 Fluorescence index versus $\mathrm{pH}$ and CDOM concentrations

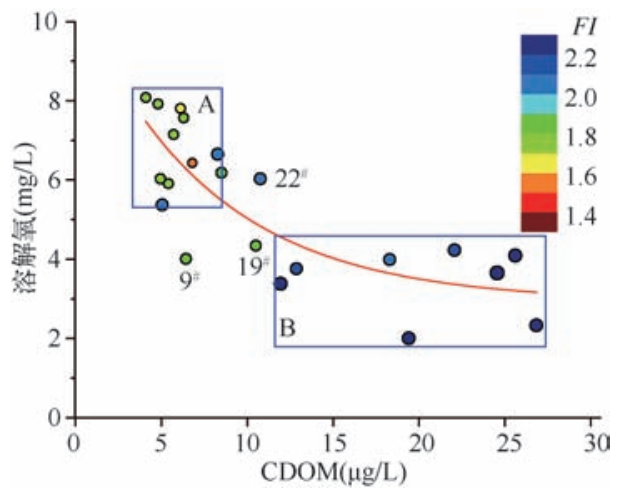

图 9 苂光指数与溶解氧、CDOM 浓度的关系

Fig. 9 Fluorescence index versus DO and CDOM concentrations

\section{3 结论}

太湖开阔湖区和河道出/入湖口附近水体的电导率、营养盐等水质指标和吸收系数较低, CDOM 菼光强 度较弱,而引、排水河道中段水体由于此时没有引水而两岸受污染河网的汇人, 上述指标均明显偏高. 从 $S$ 值分析可知望虞河受外源影响最大, 且 $S$ 值与 $a(355)$ 呈指数负相关关系. 三维苂光分析发现了 5 种苂光团, 其中类蛋白荧光峰明显强于类腐殖质苂光峰. 显然, 河流人湖后 CDOM 受外源影响减少, 主要是以微生态系 统的本地生产为主, 而河道局部水域 CDOM 受到外源输人的影响, 引起以类蛋白为主的苂光强度增加. 这主 要受城镇污废水排放活动的影响, 也与污水微生物对藻类来源的非菼光性 DOM 利用并转化为 CDOM 的过 程有关.

致谢: 野外采样和样品分析中分别得到了肖宜华博士和姜德刚博士的帮助,谨表谢意.

\section{4 参考文献}

[ 1 ] Coble PG. Characterization of marine and terrestrial DOM in seawater using exciting-emission matrix spectroscopy. Marine Chemistry, 1996, 51 : 325-346.

[ 2 ] Biers EJ, Zepp RG, Moran MA. The role of nitrogen in chromophoric and fluorescent dissolved organic matter formation. Marine Chemistry, 2002, 103: 46-60.

[ 3 ] 朱晓敏,黄清辉,李建华. 咸水藻水华期溶解有机质光谱特征变化的模拟. 中国环境科学,2009, 29(1): 68-72.

[ 4 ] Bricaud A, Morel A, Prieur L. Absorption by dissolved organic matter of the sea (Yellow substance) in the UV and visible domains. Limnology and Oceanography, 1981, 26(1) : 43-53.

[ 5 ] 张运林,秦伯强. 梅梁湾、大太湖夏季和冬季 CDOM 特征及可能来源分析. 水科学进展,2007,18(3): 415-423.

[6] 陈晓玲,陈丽琼,于之峰等. 长江中游湖泊 CDOM 光学特性及其空间分布对比. 湖泊科学,2009,21(2): 248-254.

[ 7 ] Rochelle-Newall EJ, Fisher TR. Chromophoric dissolved organic matter and dissolved organic carbon in Chesapeake Bay. Marine Chemistry, 2002, $77: 23-41$.

[8] 张运林, 秦伯强, 杨龙元. 太湖梅梁湾有色可溶性有机物的空间分布及光学行为. 湖泊科学, 2006, 18 (4): 319-324.

[ 9 ] 程远月, 郭卫东, 胡明辉. 近岸沉积物在悬浮期间所释放溶解有机物的苂光特征. 地球化学, 2008, 37(1): 51-58.

[10 ] Cory RM, McKnight DM. Fluorescence spectroscopy reveals ubiquitous presence of oxidized and reduced quinones in dissolved organic matter. Environment Science and Technology, 2005, 39: 8142-8149.

[11] 宋玲玲,仇雁翎, 张洪恩等. 淀山湖有色可溶性有机物的光谱吸收特性. 湖泊科学, 2007, 19(3): 250-254.

[12］韩宇超,郭卫东,程远月. 海洋 CDOM 光吸收研究中若干问题的探讨. 台湾海峡,2005, 24(3): 289-298.

[13] 傅平青, 吴丰昌, 刘丛强等. 高原湖泊溶解有机质的三维荧光光谱特性初步研究. 海洋与湖沼, 2007, 38 (6) : 
512-520.

[14] 张运林, 张恩楼, 刘明亮. 云南高原湖泊有色可溶性有机物和颗粒物光谱吸收特性. 湖泊科学, 2009, 21 (2): 255-263.

[15] Yang F, Huang QH, Li JH et al. Characterization of chromophoric dissolved organic matter in the Yangtze Estuary by absorption and fluorescence spectroscopy. Journal of Environmental Science for Sustainable Society, 2007, 1(1) : 55-60.

[16] Guo Lucie. Doing battle with the Green Monster of Lake Taihu. Science, 2007, 317(5842) : 1166.

[17] 孔繁翔. 太湖水危机的警示. 中国科学院院刊,2007,22(4): 267-268.

[18] Yang M, Yu J, Li Z. Lake Taihu not to blame for Wuxi's woes. Science, 2008, 319: 158.

[19] Stedmon CA, Markager S, Bro R. Tracing dissolved organic matter in aquatic environments using a new approach to fluorescence spectroscopy. Marine Chemistry, 2003, 82 : 239-254.

[20] Schwarz JN, Kowalczuk P, Kaczmarek S et al. Two models for absorption by coloured dissolved organic matter. Oceanologia, 2002, 44(2) : 209-241.

[21] Stedmon CA, Markager S, Kaas H. Optical properties and signatures of chromophric dissolved organic matter ( CDOM) in Danish Coastal Waters. Estuarine, Coastal and Shelf Science, 2000, 50 : 267-278.

[22］曹雪华,周 锷. 望虞河引水对常熟市西岸地区水环境的影响. 水资源保护,2006,22(6): 47-50.

[23] 徐 慧, 韩 青. 常熟市望虞河西岸地区排水通道问题. 水资源保护,2008, 24(1): 72-75.

[24] 段洪涛,马荣华,孔维娟等. 太湖沿岸水体 CDOM 吸收光谱特性. 湖泊科学,2009, 21(2) : 242-247.

[25] 王 林, 赵东至, 傅云娜等. 黄色物质吸收系数 $a_{g}$ (440) 与斜率 $S_{g}$ 相关关系. 大连海事大学学报, 2007, 33(S2): 179-182.

[26] 刘明亮, 张运林, 秦伯强等. 太湖人湖河口和开敞区 CDOM 吸收和三维苂光特征. 湖泊科学, 2009, 21 (2): 234-241.

[27] Baker A. Fluorescence excitation-emission matrix characterization of some sewage impacted rivers. Environment Science and Technology, 2001, 35: 948-953.

[28] 傅平青, 刘从强, 吴丰昌等. 溶解有机质的三维苂光光谱特征研究. 光谱学与光谱分析, 2005, 12 (25) : 2024-2048.

[29] Rochelle-Newall EJ, Fisher TR. Production of chromophoric dissolved organic matter fluorescence in marine and estuarine environments: an investigation into the role of phytoplankton. Marine Chemistry, 2002, 77(1) : 7-21.

[30］张运林,吴生才, 秦伯强等. 太湖梅梁湾有色可溶性有机物对光的吸收. 中国环境科学, 2004, 24 (4) : 405-409.

[31 ] McKnight DM, Boyer EW, Westerhoff PK et al. Spectrofluorometric characterization of dissolved organic matter for indication of precursor organic material and aromaticity. Limnology and Oceanography, 2001, 46(1) : 38-48. 